\title{
A COISIFICAÇÃO DOS SABERES COMO MERCADORIA NA IDEOLOGIA DO COMPARTILHAMENTO
}

\author{
THE OBJECTIFICATION OF KNOWLEDGE AS A COMMODITY \\ IN THE IDEOLOGY OF SHARING \\ LA COSIFICACIÓN DE LOS SABERES COMO MERCANCÍA \\ EN LA IDEOLOGÍA DEL COMPARTIR \\ WANDERLEY ANCHIETA ${ }^{1}$

\section{REYNALDO JOSÉ GONÇALVES JÚNIOR²}

${ }^{1}$ Doutorando do Programa de Pós-Graduação em Comunicação (PPGCOM) Universidade Federal Fluminense (UFF). ORCID iD: http://orcid.org/0000-0003-0864-9288

${ }^{2}$ Mestre em Comunicação pelo Programa de Pós-Graduação em Comunicação (PPGCOM) da Universidade Federal Fluminense (UFF) e membro do Grupo de Pesquisa do Laboratório de Experiência em Engajamento e Transformações da Audiência (LEETA) na mesma instituição.

\section{RESUMO}

Neste artigo dissertaremos sobre o papel do conhecimento na sociedade do século XXI e como a indústria editorial passou a ditar as regras no que diz respeito à produção e divulgação dos conteúdos científicos. Trabalharemos com a perspectiva de um mercado científico voltado à coisificação dos saberes como mercadoria e ao fortalecimento do senso mercantil da produção de conhecimento. Abordaremos as relações de trabalho dentro da lógica de atuação do mercado proposta pelo oligopólio editorial, assim como mencionaremos a atuação do sujeito pesquisador na construção de sua carreira em meio às regras colocadas pela ideologia do compartilhamento mercantilizado, o que interfere com o próprio ethos científico.

Palavras-chave: Ciência. Conhecimento. Compartilhamento. Mercantilização. Indústria Editorial. 


\section{ABSTRACT}

In this article we will discuss the role of knowledge in 21 st century society and how the publishing industry began to dictate the rules regarding the production and dissemination of scientific content. We will work with the perspective of a scientific market focused on the objectification of knowledge as a commodity and the strengthening of the mercantile sense of knowledge production. We will approach the labor relations within the logic of market action proposed by the editorial oligopoly, as well as to mention the researcher's role in the construction of its career amid the rules set by the ideology of marketed sharing, which interferes with the scientific ethos itself.

Keywords: Science. Sharing. Knowledge. Publishing industry. Commodification.

\section{RESUMEN}

En este artículo discutiremos el papel del conocimiento en la sociedad del siglo XXI y cómo la industria editorial comenzó a dictar las normas relativas a la producción y difusión de contenidos científicos. Trabajaremos con la perspectiva de un mercado científico centrado en la cosificación de los saberes como mercancía y el fortalecimiento del sentido comercial de la producción de conocimiento. Abordaremos las relaciones de trabajo dentro de la lógica de acción del mercado propuesta por el oligopolio editorial, además de mencionar la actuación del investigador en la construcción de su carrera en medio a las reglas puestas por la ideología del compartir mercantilizado, que interfiere con el propio ethos científico.

Palabras clave: Ciencia. Compartir. Conocimiento. Industria editorial. Mercantilización.

\section{INTRODUÇÃO}

Os pesquisadores, através da ideologia do compartilhamento, transferem sua força produtiva intelectual às editoras comerciais que lucram a partir de suas produções, buscando agregar capital social e cultural entre seus pares. Desse modo, por mais que se possa ter vantagens em utilizar as diversas plataformas digitais como forma de compartilhar amplamente suas produções, os pesquisadores estariam corroborando para a lógica de desvalorização da mão de obra tratada por Marx em seu Manuscrito econômico-filosófico (2004), no qual o teórico aponta para o fato de que a labuta não cria apenas objetos, como também torna os próprios trabalhadores numa mercadoria na mesma proporção em que se produz bens. Dentro da ideologia de compartilhamento, a produção científica e seus 
mecanismos de divulgação dos conteúdos corroboram para a máxima marxista de que a venda é a prática da alienação.

A pesquisa é o fruto da labuta, o produto que terá seu valor qualificado dentro do processo de editoração, porém, os pesquisadores passam a construir sua imagem focados na autopromoção como meio de atingir níveis cada vez maiores de visibilidade. O nexo liberal busca um elo que lhe ofereça legitimidade de como fomentar "as perspectivas gerais da sociedade de mercadorias como limites inquestionáveis de suas próprias aspirações” (MÉSZÁROS, 2006, p. 263-4, apud JOVINO, 2012, p. 74).

Nesse contexto, existe uma negociação entre tornar-se reconhecido e a exploração da força produtiva como potencial gerador da mercantilização da mão de obra intelectual. Nosso propósito é apresentar neste artigo uma reflexão sobre os caminhos que a ciência trilha neste novo período histórico, onde os sistemas produtivos se adequam a dinâmica das tecnologias. Consideramos neste artigo o papel do próprio pesquisador perante às práticas editoriais e como eles se relacionam com as políticas propostas pelo mercado editorial e suas lógicas de publicação. Refletiremos como as práticas mercantis na produção científica afetam a qualidade e relevância das pesquisas que ficam sujeitas muitas das vezes às exigências de um mercado cada vez mais dinâmico e disputado.

\section{A PRODUÇÃO CIENTÍFICA EM MEIO A QUARTA REVOLUÇÃO TECNO/INDUSTRIAL: DIVISÃO SOCIAL DO TRABALHO (CONHECIMENTO) E DIVISÃO CAPITALISTA DO TRABALHO (MERCADORIA)}

Dentro dos paradigmas colocados para o século XXI, e na forma como as relações laborais e a divisão do trabalho se alteraram perante uma dinâmica na qual o emprego da tecnologia afeta cada vez mais a prática laboral, mudanças significativas foram experimentadas desde o início da segunda revolução industrial. Os interesses capitalistas dos 
setores produtivos e industriais em meados do século XIX, com o desenvolvimento dos setores energéticos e químicos, deram lugar a uma economia pautada pela informação e principalmente pelo poder de fazer circular essas informações. Desta forma, o trabalhador passa a se adaptar a comportamentos relacionados ao uso das tecnologias voltadas à circulação de informação. Para Marques e Lazzarini,

A intensificação do uso de TI exige mudanças tanto de comportamento quanto na relação entre os diferentes setores e escalões dentro da estrutura organizacional o que, via de regra, impacta fortemente a gestão de recursos humanos como um todo. (MARQUES, LAZZARINI, 2002, p. 07).

$\mathrm{Na}$ tentativa de se adaptar a essa realidade, se faz necessário analisar a nova divisão capitalista do trabalho para entender como se efetua a relação do sujeito com a sociedade e de que forma o capital se apropria da mão de obra. Karl Marx e Friedrich Engels (1986) apontam que os diversos estágios de desenvolvimento da divisão do trabalho passam a representar diferentes formas de propriedade, assim, mantendo as fases de desenvolvimento sob o controle de quem detém a propriedade sobre determinado meio produtivo. Os autores defendem que cada novo estágio na divisão do trabalho determinará, na mesma proporção, as relações entre os indivíduos no que diz respeito ao fruto do trabalho: ou seja, o capital produzido através da venda de sua mão de obra.

Para Marx, a divisão do trabalho leva em conta uma separação entre o trabalho na indústria, no campo e no comércio, cujas propriedades passaram a representar diferentes formas de propriedades, assim como das relações trabalhistas. Em A ideologia alemã, Marx (1979, p. 09) defende que: "São os homens que produzem às suas representações, as suas ideias, etc". Dessa forma, Marx aponta para o fato que não existe propriedade sobre a produção intelectual que não a do próprio indivíduo, que teoricamente possuiria direito ao que produziu através de suas ideias. Para o Marxismo, a produção intelectual, o labor no campo das artes, filosofia, ciências, metafísica e do direito, ou seja, a reprodução das 
representações e da consciência, estão visceralmente ligadas às experiências e atividades materiais. Assim sendo, todo produto intelectual é a representação das experiências cotidianas na qual os sujeitos estão inseridos, experimentados e conscientes. Mikhail Bakhtin defende que

A consciência adquire forma e existência nos signos criados por um grupo organizado no curso de suas relações sociais. Os signos são o alimento da consciência individual, a matéria de seu desenvolvimento, e ela reflete sua lógica e suas leis. A lógica da consciência é a lógica da comunicação ideológica, da interação semiótica de um grupo social. (BAKHTIN, 2006, p. 34).

Dado que representações, ideologias e organização do trabalho são fruto da capacidade humana de absorver significantes e significados, o que se questiona é a concepção de pertencimento da produção intelectual. Nesse caso, é preciso observar o conhecimento pelo aspecto do seu valor como mercadoria, já que no modo de produção capitalista, toda atividade laboral visa criar objetos que tenham valor de uso. Assim a produção do conhecimento, através do trabalho intelectual, passa a gerar objetos que de alguma maneira serão consumidos e recebam um valor de troca respectivo. Marx entende que se toda mercadoria, ou seja, qualquer fruto de dedicação laboral, tem um valor de uso, automaticamente ela passa a ter um valor de troca na mesma proporção. De fato, o que ocorre é que nas sociedades capitalistas onde quase todas as esferas da vida são monetizadas, fetichizadas e pautadas no consumo, o conhecimento científico, assim como as outras esferas do trabalho intelectual, apenas terá valor corrente se também apresentar um valor de troca.

A mercadoria é, antes de mais nada, um objeto externo, uma coisa que, por sua propriedade, satisfaz necessidades humanas, seja qual for a natureza, a origem dela, provenham do estômago ou da fantasia. Não importa a maneira como a coisa satisfaz a necessidade humana, se diretamente, como meio de subsistência, objeto de consumo, ou indiretamente, como meio de produção. (MARX, 1994, p.41 apud TREIN \& RODRIGUES, 2011). 
À vista do exposto, os grandes proprietários dos meios produtivos, a classe que dispõe dos meios de produção material, detém na mesma proporção os meios de produção intelectual. Por consequência, a classe trabalhadora não detentora dos meios de produção, ficará submetida à classe dominante no que diz respeito ao que Marx e Engels colocam como a expressão ideal das relações materiais dominantes concebidas sob a forma de ideias. Em outras palavras, o que fortalece a classe dominante é o poder de expressar o seu domínio através das ideias, e isso se refletiu de forma muito objetiva nos valores empregados dentro das sociedades capitalistas no que diz respeito à educação.

Dentro das instituições educacionais, responsáveis por transmitir para a sociedade os saberes científicos, técnicos, filosóficos e artísticos, o que se viu foi um grande aprofundamento das relações entre os valores educativos e os interesses do capital. Houve uma apropriação institucionalizada das narrativas históricas e teóricas para que se atingisse o propósito de transmissão dos valores pertinentes à manutenção da ordem e dos interesses do capital financeiro. Para a manutenção do status quo, apontam Celi Taffarel e Joelma Albuquerque (2009), não poderia haver outra opção como alternativa à gestão das sociedades, senão a subordinação estrutural e a total dependência dos princípios defendidos pelos interesses do capital. O princípio do conhecimento como uma mercadoria com valor de uso tem como consequência sua potencialização como instrumento de troca, ou seja, o conhecimento passa a agregar um valor quantificável para permuta. Ele passa a ser comprável e dessa forma pode sofrer influências para que a produção intelectual não possua somente o princípio da verdade, como também pode se moldar aos interesses de quem vai pagar por ela. Partindo desse pressuposto, a produção intelectual se afasta de seu sentido social amplo, onde é tida como um bem coletivo, passando a reverberar uma vertente mercadológica que atende à lógica da manutenção dos poderes vigentes. Desse modo,

Sendo uma realidade, não só nos EUA, mas também como tendência crescente no resto do mundo, o estreitamento das relações entre algumas das principais universidades e as grandes empresas, 
multiplicam-se os casos de influência destas últimas nas investigações dos cientistas: publicação de artigos tendenciosos, atraso ou mesmo não publicação de resultados, restrição nos temas abordados, apropriação privada dos resultados das teses acadêmicas. (MARTINS \& GARCIA, 2009, p. 84).

Portanto não há uma dissociação separativa entre o labor material e o imaterial. Ao final, todos são operários que alimentam o sistema produtivo. Neste cenário, como forma de se adaptar as mudanças promovidas pela revolução tecnológica do século XXI, os trabalhadores tendem a se colocar em posições que garantam sua permanência dentro do mercado de trabalho. Dessa forma, o exercício contínuo da venda da autoimagem (autobranding) se tornou um item obrigatório do mundo em rede (compartilhado) da atualidade.

\section{O CONHECIMENTO COMO MERCADORIA}

A lógica de funcionamento do setor editorial impõe aos pesquisadores uma cultura da meta e do autobranding como pré-requisitos para se almejar determinado reconhecimento dentro da comunidade científica. Desta forma, para além dos interesses pelo lucro dos grandes investidores e empresas do setor, existe o papel do trabalhador, da categoria que detém a força de produção num setor da economia que em 2017 faturou cerca de $19^{1}$ bilhões de libras esterlinas. Stephen Buranyi (2017) salienta que, somente em 2017, o lucro da ReedElsevier, gigante do mercado editorial científico, foi superior ao de empresas como Google, Apple e Amazon. Conclui-se, desse modo, que o pesquisador, responsável pelo desenvolvimento da pesquisa e manufatura do produto final, assim como nas demais categorias laborais, tem seu ofício alienado. Isto posto, o processo de alienação torna o trabalho estranhado ${ }^{2}$, onde não existe a apropriação da sua própria produção, e o pesquisador

\footnotetext{
${ }^{1}$ Cf. em < https://www.theguardian.com/science/2017/jun/27/profitable-business-scientific-publishing-badfor-science $>$. Acesso em 01.10.19.

${ }^{2}$ Para a teoria marxista, o trabalho estranhado diz respeito a formação capitalista de produção.
} 
acaba por entregar os direitos autorais para uma empresa que deterá o direito sobre o produto final. No mundo das mercadorias, defende Cristiane Ribeiro em consonância com os princípios de Marx (2015, p. 36), o homem é o principal insumo para que se haja a produção, é através da utilização da força de trabalho do outro que se gera lucro.

Dentro deste cenário, no qual a matéria prima que move esta indústria é o conhecimento, muitos questionamentos são feitos em relação ao verdadeiro papel destas grandes editoras na divulgação da produção científica ao redor do mundo. No Brasil, financiados pelos governos, na maioria das vezes, a produção científica fica a cargo do pesquisador, que por conta própria propõe uma direção ao seu trabalho e o desenvolve. Ou seja, a labuta é responsabilidade do cientista. No momento posterior, o da publicação, as revistas em geral não arcam com os custos dos revisores que medem a qualidade do artigo e sua efetividade como produto de conhecimento válido. Uma vez aprovados para a publicação, os artigos são entregues de forma gratuita aos editores comerciais que os vendem para bibliotecas públicas. Estas, financiadas pelos governos, ou limitam o seu acesso para o leitor através de uma definição de valores específicos ou são entregues a editores que liberam o conteúdo de forma aberta.

Em junho de 2017, Stephen Buranyi publicou um artigo no site inglês do The Guardian intitulado "The long read. Is the staggeringly profitable business of scientific publishing bad for science?". No artigo o autor se propôs a fazer um raio-x do funcionamento da indústria de publicação científica, expondo suas ferramentas e padrões de funcionalidade. Através do texto o autor desnuda alguns mitos, como também as estratégias utilizadas pelas grandes revistas do setor para elevar seus lucros, principalmente envoltos ao uso das tecnologias de comunicação e compartilhamento de dados. Para Buranyi (2017), os pesquisadores estão conscientes de que as relações entre eles e as regras vigentes para publicações no mercado editorial são um mau negócio e que essas relações, nas palavras do autor, são perversas e desnecessárias. Isso se reflete na realidade brasileira, onde revistas com 
qualis $^{3}$ superiores são almejadas como fator de valorização para suas pesquisas e consecutivamente para oferecer mais visibilidade ao autor.

Iniciativas de open access crescem dentro desta lógica de dominação do mercado editorial. Cada vez mais pesquisadores abrem o acesso de suas produções a repositórios institucionais de acesso livre, que são utilizados como forma de disseminação de publicações científicas. Neste modelo, autores podem disponibilizar seu conteúdo já publicado ou aceito de forma aberta com consentimento do editor (via verde) ${ }^{4}$, ou pela (via dourada) ${ }^{5}$ que promove o livre acesso a conteúdos científicos sem nenhuma restrição.

No Brasil, algumas revistas de determinadas áreas do conhecimento, além do processo de aceitação através da revisão por pares, ainda cobram taxas para o autor poder publicar. Mesmo as revistas que trabalham com pesquisas em acesso livre, cobram de seus pesquisadores os direitos autorais sobre a obra terminada que será publicada, ou seja, existe a alienação do produto através da detenção sobre seus direitos autorais, tirando-os do autor. Algumas revistas como a Sage, Taylor, entre outras, utilizam o modelo de article processing charge (APC), cobrando taxas do autor para disponibilizar o conteúdo em acesso aberto ou híbrido, de qualquer forma o pagamento destas taxas, não garantem ao autor propriedade sobre o conteúdo referido.

O pesquisador entrega de forma gratuita às editoras o fruto de seu processo laboral, com horas acumuladas de trabalho que envolve pesquisas de campo, vasta revisão bibliográfica e produção textual, editoras que terminam por lucrar com o produto final. Desta forma, essa relação entre pesquisador, o produto e o mercado superaria ao conceito de maisvalia, uma vez que a remuneração pelas horas empregadas na produção laboral não parte de

\footnotetext{
${ }^{3}$ O Qualis constitui-se num sistema brasileiro de avaliação de periódicos, mantido pela CAPES. Relaciona e classifica os veículos utilizados para a divulgação da produção intelectual dos programas.

${ }^{4}$ É um arquivamento da produção científica que pode ser feito pelo próprio autor do artigo já publicado ou aceito para publicação, a partir do sinal verde do editor, para que o documento seja disponibilizado.

${ }^{5}$ Promove a criação de revistas de acesso aberto, ou seja, está relacionada com a produção de artigos científicos em periódicos eletrônicos, cujo acesso é livre na web sem que haja restrição quanto ao seu uso, sendo disponibilizado pelas próprias revistas científicas.
} 
quem passa a deter o direito sobre as pesquisas. Assim, o periódico que passa a deter os direitos autorais sobre a pesquisa não paga absolutamente nada para o pesquisador, para o trabalhador que dedicou horas laborais para produzi-la. A mais-valia é a condição de exploração do capitalismo sobre a classe trabalhadora, ou seja, a classe que oferece a força de trabalho em troca de um salário, desta forma trocando sua produção por um valor abaixo daquele cobrado pelo produto no mercado.

A mais-valia, segundo Marx (2004), é a diferença entre o valor do produto e o valor do capital necessário para produzi-lo, o valor acrescido no produto, local onde se configura a apropriação deste valor pelos capitalistas. Marx entende que é o trabalho que agrega valor a determinado produto, assim o valor da mão de obra empregada na produção de determinado produto, corresponde à sua valorização. Lembremos, pois, que no sistema capitalista quem detém a propriedade sobre os meios de produção não é a classe trabalhadora, mas os donos do capital. Assim, o trabalhador precisa vender sua mão de obra ao proprietário dos meios de produção. Como o trabalhador não consegue vender por conta própria o que produz, acabam por vender a sua força de trabalho, assim gerando valia para os capitalistas.

No marxismo, o empregador, nesse caso, as editoras, pagaria um valor pelo produto que representa um percentual muito aquém do seu valor de mercado final. Porém, na lógica capitalista da indústria editorial científica online e compartilhada, as empresas lucram e na maioria das vezes não pagam nada em retorno nem para o pesquisador, nem aos revisores que avaliam a qualidade da produção e legitimam a validade do conhecimento gerado na pesquisa.

Para além das manifestas regras que visam a mercantilização ou coisificação do processo de publicações, um outro fato que atenta para um absoluto controle do nexo mercantil no setor é a condição em que muitos pesquisadores se colocam como forma de atender determinada demanda, de certa forma estipulada pelo oligopólio editorial. Indagações sobre a isenção de pesquisas reguladas por essa lógica, como também até que 
ponto isso pode influenciar nos resultados das mesmas, são de premência absoluta no momento.

As relações entre produção de conhecimento e interesses mercantis coloca em voga um quesito básico de reflexão por parte do cientista, do sujeito que tem como função gerar uma maior compreensão da realidade objetiva, portanto construir novos conhecimentos. Qual o lugar da produção de novos conhecimentos, uma vez inseridos nas distorcidas lógicas de acúmulo do capital? Graça Caldas (2011) oferece uma reflexão em relação ao valor do conhecimento. Ela defende que a cultura científica implica no desenvolvimento da capacidade crítica e uma mais afinada leitura da realidade objetiva, ou seja, a ciência tem como pressuposto oferecer à sociedade além de inovação e tecnologia, uma ampliação da visão sobre o factual.

A autora aponta para o valor do impacto da educação científica na formação e desenvolvimento de uma sociedade atenta à realidade e que esteja preparada para lidar com as situações mais complexas da vida. Caldas coloca como função primacial do conhecimento a emancipação social do sujeito, parte fundamental para a conquista de uma cidadania plena e consciente. O que se indaga, é sobre o papel da sociedade civil organizada dentro deste processo e as atribuições dos mais diversos setores na formulação de políticas científicas e sua disseminação na sociedade, principalmente o papel do Estado.

Edwards e Siddhartha (2016) atentam para o fato de que na atual conjuntura do quadro especializado dentro dos ambientes de pesquisas, a carreira profissional passou a ser concebida pelo foco das realizações pessoais, pela perspectiva do indivíduo e não pelo mérito pautado no altruísmo em seu fazer ciência e produzir conhecimento para o bem da sociedade. Para os autores, o fato é que estes profissionais, imersos em um ambiente cada vez mais pautado pela lógica da superprodutividade, deixam-se induzir por condutas que tenham como objetivo reverberar a lógica de competição e autobranding incentivada pela indústria editorial científica. Desta forma, a julgar pelos fatos observados dentro do ambiente acadêmico, e como a conduta do sujeito pesquisador possa ir ao encontro do que se vem 
afirmando sobre as relações de poderes dentro da academia, verificamos uma forte tendência à coisificação da pesquisa numa direção mercadológica.

Edwards e Siddhartha (2016) ainda expõem o perigo de se enfatizar a produção em detrimento da qualidade das pesquisas. Quanto maior é a busca por reconhecimento e nível de publicação, que se aferem pelo maior compartilhamento via redes tecnológicas, menos tempo hábil o pesquisador terá para desenvolver pesquisas que possam se tornar mais relevantes para a comunidade de forma geral. Desta forma, o risco é de se criar um sistema que, segundo palavras dos autores, se torne uma "perversão da seleção natural”, assim, sendo valorizados os pesquisadores que sejam receptivos às políticas e incentivos mercantis dentro da indústria de produção científica. Por conseguinte, os pesquisadores por mais éticos que possam ser em suas posições sobre a concorrência dentro dos campos científicos, podem tomar medidas convenientes para conseguirem se manter superprodutivos e representativos perante o compartilhamento exigido pela comunidade científica, em suas áreas específicas de conhecimento.

Robert Merton (1985, p. 357) discorre sobre o Ethos científico, o definindo como algo "complexo, com ressonâncias afetivas, de valores e normas que se consideram obrigatórias para o homem de ciência". Segundo Rosana Salvi e Irinéa Batista (2007), os valores pregados institucionalmente são absorvidos pelos pesquisadores de forma que através destes princípios, criam-se parâmetros de atuação que orientam os mesmos a determinados modos de condutas e pensamentos. Portanto, existe uma estrutura normatizante que faz com que os sujeitos ajam de forma a dar legitimidade aos preceitos ali estabelecidos. As autoras defendem que a reflexão sobre a obra de Merton e seu argumento sobre a ethos científica justificariam as condutas dos cientistas, os paradigmas compartilhados dentro da comunidade científica e a influência para além dos muros das universidades. Assim como a própria lógica mercadológica da produção científica como manufatura de conhecimento em forma coisificada de produtos colabora para a construção dos campos de disputas dentro do universo científico. 
A comunidade científica, concebida como unidade analítica para o estudo social da ciência, é o grupo dos indivíduos reunidos por elementos comuns em sua educação e aprendizado e caracterizados pela relativa plenitude de sua comunicação profissional e relativa unanimidade de seu julgamento profissional. (SALVI e BATISTA, p. 03, 2014).

José Luiz Garcia e Hermínio Martins (2009) dissertam sobre as transformações do fazer científico no século XXI e as mudanças de seu ethos. Os autores discorrem sobre os valores objetivos dos setores comerciais e suas influências sobre as pesquisas científicas e apontam numa direção da submissão comercial da ciência, que vem alterando seu ethos. Esse processo, no final do século XX e início do século XXI, tornou-se um campo fértil para o surgimento de iniciativas, como o exemplo de startups que deram "origem a um vasto leque de subcontratação dos saberes e do saber-fazer" (GARCIA; MARTINS, 2009, p. 86). Desta forma, ligadas diretamente aos setores capitalistas e transnacionais, as pesquisas incentivadas por essas instituições passaram a ter um caráter comercial, cuja prioridade seria apenas de gerar lucro para determinadas instâncias.

As pressões para induzir uma cultura de mercantilização dentro do campo da pesquisa podem ser apontadas não somente como uma forma de aumentar os lucros provindos das pesquisas para as grandes empresas de publicação editorial, mas também servir de apoio aos interesses de setores ligados diretamente ou não à produção acadêmica. Casos relacionados às pesquisas patrocinadas por determinados setores que tenham como finalidade a afirmação própria dos interesses da empresa sobre algum assunto e não apenas a perspectiva em se produzir um conhecimento fiel a realidade são práticas conhecidas por toda a comunidade científica. Seguindo a mesma lógica, muitos trabalhos supostamente científicos são encomendados, ou seja, já nascem com o propósito de dar alguma base científica a determinada questão que é do interesse de determinada instituição. Muitas das vezes pesquisadores sérios e comprometidos com o ethos científico se veem censurados ou mesmo perseguidos por defender posicionamentos que possam contrariar alguns interesses. 
Um acontecimento que fornece um exemplo claro desse tipo de prática na qual muitos pesquisadores sofrem, foi o caso do Pesquisador da Fiocruz ${ }^{6}$ (Fundação Oswaldo Cruz) Ceará, Fernando Carneiro. Em fevereiro de 2018 a entidade lançou nota pública de repúdio contra a censura por seu pesquisador que vinha denunciando, junto ao Ministério Público do Estado, os perigos do uso de agrotóxicos e seus efeitos sobre a saúde pública. Fernando apresentou um relatório onde mostrava que o estado do Ceará era o terceiro maior comercializador de agrotóxicos do país. Após sua apresentação, o pesquisador passou a ser alvo de críticas, constrangimentos e perseguições, inclusive sendo interpelado juridicamente por uma ação judicial movida pela Federação da Agricultura e Pecuária do Estado do Ceará (FAECT).

Dentre as solicitações feitas pela FAECT judicialmente foi a de que o pesquisador não deveria mais usar o termo "veneno" ao se referir aos agrotóxicos, e sim o termo “defensivos agrícolas", posição essa que fere a própria legislação nacional que conceitua tais substância como agrotóxicos ou veneno. Outras instituições como por exemplo a Associação Brasileira de Saúde Coletiva (ABRASCO), se manifestaram a favor de Fernando Carneiro e contra a interpelação judicial da FAECT. Esse caso clarifica bem como algumas políticas são implantadas dentro do ambiente científico como forma de censurar alguns pesquisadores que possam desenvolver pesquisas que vão de encontro ao interesse de alguns setores mercantis. Nesse caso, a Federação da Agricultura e Pecuária do Estado do Ceará, instituição essa que representa o poder do agronegócio no estado.

Esses são alguns dos exemplos de organizações privadas interferindo diretamente tanto na produção do conhecimento quanto na disseminação a nível social de seus resultados apenas como forma de proteger seus interesses. Neste cenário, o pesquisador fica sujeito as regras da indústria editorial científica, assim como a interesses comerciais de diversos

\footnotetext{
${ }^{6} \mathrm{Cf}$. em $<$ https://agencia.fiocruz.br/fiocruz-divulga-nota-publica-contra-censura-de-pesquisadores $>$. Acesso em 30.10.19.
} 
setores. Desta forma, o mercado científico se torna um lugar onde a concorrência ultrapassa as fronteiras da produção científica, fazendo com que a autoimagem, o nível de produtividade e o poder de compartilhamento se torne prática cotidiana no circuito acadêmico.

\section{A MERCADORIA (CONHECIMENTO) COMPARTILHADA}

Assim afirmamos que a alienação da força de trabalho representa o cerne das relações laborais no setor científico. O sistema de gerência empresarial do mercado acadêmico acaba por fazer prevalecer uma dinâmica auto-empreendedora por parte do pesquisador. Sites de compartilhamento como Academia.edu e Reseachgate, por exemplo, serviriam como uma espécie de espaço pós-laboral, como uma vitrine, onde os pesquisadores propagandeiam suas conquistas em busca do reconhecimento pelo trabalho desenvolvido. O reconhecimento se torna fator essencial na motivação ao engajamento, pois divulgar seus méritos é a materialização do capital social e profissional. Cada etapa concluída, metrificada e mercantilizada, representa mais uma etapa vencida ao ponto que se progride em relação a sua autoimagem. Assim, ao vencer os obstáculos de cada etapa, o pesquisador está apto a compartilhar suas conquistas com seus pares através das plataformas determinadas.

As conquistas obtidas com o passar do tempo são fatores de estímulos para que se continue produzindo de forma a estabelecer maior qualificação da própria imagem, assim como também da própria produção de suas pesquisas. O prêmio conquistado com o engajamento científico é o reconhecimento de seus pares, podendo gerar maior número de citações e consecutivamente de reconhecimento no mercado científico editorial. A lógica de se adequar às demandas do mercado de trabalho em meio a quarta revolução tecnológica reflete as novas formas de performances sociais promovidas pelos usos das tecnologias da informação. O trabalhador contemporâneo excede as tradicionais práticas laborais no que diz respeito à manufatura de seu produto. No campo da produção imaterial, onde o status do agente pode determinar a relevância de uma obra, a capacitação reconhecida e a autoimagem passam a designar um valor pré-concebido ao produto final. Perante ao cenário exposto, o 
ato de realizar autobranding passaria como mais uma postura assumida pelo trabalhador em sua rotina laboral.

Kjeldgaard e Askegaard (2002) investigam o autobranding, oferecendo uma visão de que determinadas pessoas ostentam em seus corpos e comportamentos variados símbolos que tem como objetivo compor uma imagem idealizada. Para os autores, a marca é como um portador de significados, assim como uma via de estruturação dentro da lógica do mercado globalizado. Usando como método as noções de mediascape de Appadurai, os autores defendem a centralidade da marca como fator de análise dos sujeitos atuantes. A marca tornase carregada de significados e associações, que podem se expressar de formas negativas ou positivas. À vista disso, a prática do autobranding no campo acadêmico teria como objetivo sempre colocar a imagem do pesquisador como bem vista perante o circuito científico.

Neste cenário, o uso de plataformas digitais e redes sociais especializadas, com alcance muito amplo em determinados nichos, servem como uma ferramenta que propicia um poder de compartilhamento da autoimagem, acompanhadas dos atributos profissionais. Para além do ambiente acadêmico, hoje o potencial de compartilhamento não é apenas das produções científicas, mas também da própria imagem e da forma como ela é constituída para o mundo.

Hoje, as redes sociais e de forma mais ampla os ambientes virtuais colaboram para que os muros institucionais das academias sejam transpassados. Com a utilização das redes sociais especializadas ou as mais convencionais, se fortalece a lógica do compartilhamento e consecutivamente também o ciclo do autobranding. Assim, de forma progressiva, as práticas acadêmicas se adequam à lógica do mercado capitalista, da produção e da atribuição de valor de mercadoria aos seus produtos. O papel do sujeito pesquisador, por mais que venha a ser crítico dessa lógica vigente, não é necessariamente de uma aceitação cega dessas regras, mas da disposição em jogar o jogo para não perder. A hipercompetitividade no mercado profissional, nas diversas áreas de atuação, se tornou um incentivo ainda maior para a autopromoção. Ainda que conscientes de sua participação nesse "jogo", cabe a esses atores 
um posicionamento de crítico e reflexivo sobre seus papéis dentro no processo da autogestão da construção de suas carreiras e imagens.

\section{REFERÊNCIAS}

ASKEGAARD, S.; KJELDGAARD, D. Os peixes aquáticos nadam? Relações entre cultura e marketing na era da globalização. In: Perspectivas sobre relações de marketing, p. 1335, 2002.

BAKHTIN, M. Marxismo e filosofia da linguagem. Tradução de Michel Lahud e Yara Frateschi Vieira. 12a edição. São Paulo: Hucitec, 2006.

BURANYI, S. “Profitable business scientific publishing bad for science?” Disponível em: https://www.theguardian.com/science/2017/jun/27/profitable-business-scientificpublishing-bad-for-science. Acesso em: jan. 2018.

CALDAS, G. O valor do conhecimento e da divulgação científica para a construção da cidadania. In: Comunicação \& Sociedade, v. 33, n. 56, p. 7-28, 2011.

EDWARDS, M. A; SIDDHARTHA, R. Academic Research in the 21st Century: Maintaining Scientific Integrity in a Climate of Perverse Incentives and Hypercompetition. Environmental Engineering Science. In: Environmental engineering science, vol 00, n 00, pp. 51-61. Publicado em 2016. Disponível em < doi:10.1089/ees.2016.0223 > Acesso em: jul. 2018.

GARCIA, J. L.; HERMÍNIO, M. O ethos da ciência e suas transformações contemporâneas, com especial atenção à biotecnologia. In: scientiæ studia, v. 7, n. 1, pp. 83-104. Publicado em 2009. Disponível em < http://dx.doi.org/10.1590/S1678-31662009000100005 > . Acesso em: set. 2018

JOVINO, W. K. M. Marx e Mészáros: Uma Análise da Crise do Capital e da Transição Socialista. In: Indivíduo e educação na crise do capitalistmo. CHAGAS, E. F. et al (orgs). Fortaleza: Edições UFC, 2012.

MARQUES, M; LAZZARINI NETO, S. Capital humano e TI gerando vantagem competitiva. RAE-eletrônica, v. 1, n. 2, 2002.

MARX, K.; ENGELS, F. A Ideologia Alemã (Feuerbach). Tradução de José Carlos Bruni e Marcos Aurélio Nogueira. 5ª ed., São Paulo: Hucitec, 1986. 
. Manuscritos económico-filosóficos de 1844. Ediciones Colihue SRL, 2004.

MERTON, R. K. La sociología de la ciencia. Madri: Alianza Editorial, 1985.

MÉSZÁROS, I. A educação para além do capital. Tradução de Isa Tavares. São Paulo: Boitempo, 2008.

RIBEIRO, C. D. Processo de trabalho e processo de valorização: extração de mais-valia na mineração. Dissertação de mestrado, UFJF, 2015. Disponível em < https://bit.ly/32P9bK9 >. Acesso em: jul 2018.

ROCHA, A. A. N. Ideologia e dialogismo: o que de Bakhtin cabe na sala de aula. Revista Linguasagem, São Carlos/SP, 2012.

SALVI, R. F.; BATISTA, I d. L. A análise dos valores na filosofia da ciência e na educação científica. In: Anais do VI ENPEC - Encontro Nacional de Pesquisa em Educação em Ciências, v. 1, pp. 1-12. Publicado em 2007. Disponível em: < https://bit.ly/3jFy7L0 > . Acesso em: jul. 2018.

TAFFAREL, Celi. Z.; ALBUQUERQUE, Joelma. D. O. A educação para além do capital. Revista entreideias: educação, cultura e sociedade, v. 13, n. 14, 2009.

TREIN, E.; RODRIGUES, J. O mal-estar na academia: produtivismo científico, o fetichismo do conhecimento-mercadoria. Revista Brasileira de Educação, v. 16, n. 48, 2011. 